\title{
Exporing Student Teachers' Perceptions on Mentoring during School Experience at High Schools in Gauteng Province, South Africa
}

\author{
Dr Mabatho Sedibe \\ Department of Educational Psychology, University of Johannesburg, \\ P.O. Box 524, Auckland-park, Johannesburg 2006, South Africa \\ Email:mabathos@uj.ac.za
}

\section{Doi:10.5901/jesr.2014.v4n3p197}

\begin{abstract}
This study is based on exploring student teachers' perceptions on mentoring during school experience at high schools in Gauteng Province. This study is part of a larger research project conducted by the lecturers in the Department of Educational Psychology at a South African University. The study intends to give an overview results concerning mentoring student teachers during their school experience in high schools. Qualitative method was used in this study and data was collected through indepth individual interviews where one student teacher was the participant. The findings showed that mentors play an important role in the content and knowledge production and professional development of student teachers.
\end{abstract}

Keywords: Post Graduate Certificate in Education, School Experience. Teaching Practice. Mentor and Student Teachers as Mentees

\section{Introduction and the Background of the Study}

Mentoring has emerged as an effective tool and process for developing student teachers in South African Universities as it is in most cases done during pre-service and during the beginning of novice teachers' years of service. This study was conducted in 2012, focusing on the exploration of Postgraduate Diploma Certificate in Education (PGCE) student teachers' perceptions on mentoring during their school experience at high schools in Gauteng Province, South Africa. School experience in this study refers to work related experiences gained by student teachers in teaching at schools without pay. PGCE on the other hand refers to fourth year Education students who intend to be teachers, teaching in Senior (Standard 5,6 and 7) or FET phases (Standard 8,9,and 10) upon the completion of their professional diploma qualification. These students are placed to the neighbouring high schools after the University has been granted permission to accommodate their students.

The aim of conducting this study is to explore and describe student teachers' perceptions on mentoring during school experience/teaching practice at high schools as well as providing them with constructive feedback and scaffolding that will ease their initial transition into the real life teaching in a classroom setting. These students are thus placed in the neighboring high schools every year during the second semester for a period of seven weeks with an aim of practicing how to teach using different teaching strategies in classrooms consisting of diverse learners. In other words they will be putting theory taught by methodology lecturers into practice. They are expected to prepare, plan and teach lessons according to their teaching subject specialization, following the school's time table. The researcher collected data through individual interviews with one student because the study was part of a bigger project between the University of Johannesburg (UJ) in the Department of Educational Psychology, Faculty of Education and Leiden University (LU). Questions were focusing on student teachers' perceptions on mentoring during school experience at high schools in Gauteng Province, South Africa.

\section{The Aim of the Study}

The aim of this study is to explore and describe student teachers' perceptions on mentoring during school experience at high schools in Gauteng Province, South Africa. This study will thus attempt to answer the question: what are student teachers' perceptions on mentoring during school experience at high schools in Gauteng Province, South Africa? 


\section{What is Mentoring in this Study?}

The definition of the concept "mentor" is broad but in this study the researcher concurs with Bleach (1999) who describes mentors as those that provide assistance to newly qualified teachers. Hopper (2001) adds that mentors focus on the need to support and encourage the trainees to listen to them, evaluate and reflect with them, be flexible and approachable and offer time and commitment to trainees. Hopper (2001) further states that mentors embrace the characteristics of other roles such as a critical friend, a role model, assessor and adviser. Awaya, McEwan, Heyler, Linsky, Lum, \& Wakukawa (2003) refer to mentoring as a journey and a process of collaborative work. According to Zachary (2011) the mentor nurtures and develops the mentee's capacity for self- direction (from dependence to independence to interdependence) over the course of the relationship. Throughout the learning relationship, both mentoring partners share accountability and responsibility for achieving the mentee's learning goals. These characteristics are important in the teaching profession, especially from South African schools' perspective because they are also imbedded in the roles of a good teacher in the Government Gazette of South Africa (1998). This will be described in the proceeding section.

From the proceeding section, the researcher thus views mentoring as the concept which is relatively new to South African higher education institutions especially in our Department of Educational Psychology. On this note, I therefore view mentoring as an empowering process that helps student teachers to become professional teachers when guided by experienced knowledgeable teachers who introduce them /student teacher to teaching practice. Mentoring can thus be further understood as the involvement of two or more people with one being more experienced than the other, coupled with an aspect of developmental caring and sharing of skills and knowledge with an effort of enhancing one's growth. In this study the student teachers are inducted into the teaching profession with an aim of achieving professional development and personal growth by learning from the mentor. The researcher thus sums up the above discussion on the phenomenon mentoring by stating the following mentor's guide as written by Bernard (2000) that in mentoring:

- There should be support of the concept mentoring

- Availability of staff resources

- Clear objectives and evaluation measures

- Enough time allocation for staff to administer mentoring, provide orientation and training of mentors

- Defining roles and procedures during mentoring.

Mentos and Yang (2006) are in support of the proceeding section by stating that there should be a strong positive relationship between the mentor and mentee through recognizing one's strengths and weaknesses and addressing them through appropriate actions and opportunities as stated on table 1. below, extracted from Mentros and Yang (2006.

\section{Table1:}

\begin{tabular}{|l|l|}
\hline Advise, do not dictate & Actively listen and contribute to the conversation \\
\hline $\begin{array}{l}\text { Advise on what you know, admit what you don't know or refer to } \\
\text { others }\end{array}$ & $\begin{array}{l}\text { Understand your mentor will not have all of the answers-be } \\
\text { willing to look them up }\end{array}$ \\
\hline Provide relevant examples and resources & Access resources-do your homework \\
\hline $\begin{array}{l}\text { Recognize your mentee's weaknesses but build on his or her } \\
\text { strengths }\end{array}$ & Acknowledge your weaknesses but build on your strengths \\
\hline Give constructive criticism & Accept and reflect on constructive criticism \\
\hline Don't shy away from difficult conversations & Don't shy away from difficult conversations \\
\hline Periodically evaluate progress and reassess the relationship & Periodically evaluate progress and reassess the relationship \\
\hline Celebrate success and be reliable & Celebrate success and be reliable \\
\hline
\end{tabular}

\subsection{Characteristics of mentors}

According to the researcher in this study, the following characteristics on mentoring are important: a good communicator, a professional role model, a life-long learner and researcher. Tomlinson (1995) adds the following: effective coach and effective facilitator whilst Elliot and Calderhead (1994) speak of a guider, leader, a good friend, a listener and someone enabling somebody in classroom management. From the above characteristics on mentoring, as a researcher I am of the opinion that one person may not have all these characteristics and therefore this does not mean that mentors should just relax and not help mentees in achieving the goals of professional teaching. Engels (2003) sums the preceding discussions by mentioning that a good mentor is a planner, organizer, negotiator, be trusted by his colleagues, must 
have enough professional knowledge, be able to create a conducive climate of openness, value the beginning teachers' qualities, master coaching and counseling skills and also have positive attitude towards his/her profession.

\section{Theoretical Framework}

This study is focused on Vygotsky's social constructivist's theory which according to Fisher (2005) states that knowledge is constructed in a school context through language and mediation. In this study Vygotsky's theory is relevant because the mentor played a role as a mediator in scaffolding the student teacher towards the achievement of professional knowledge. The above Vygotsky's framework is complemented by Bandura's, which is the social learning (social interaction) theory. Social learning theory according to Bandura (1977) posits that people learn from one another through observation, imitation and modeling. This theory is thus also relevant because it focuses on the interaction between individuals (between learners and teachers/mentees and mentors respectively). During this interaction the learners/mentees learn through imitating and modeling the teacher/mentors as he/she demonstrates and teaches them how to be good teachers. This means that through interaction, mentees and mentors will be able to learn and share professional knowledge.

\section{Research Design and Methodology}

Leedy (2003) defines research design as the specification of methods and procedures used for acquiring information needed to solve a central problem. Henning, Van Rensburg \& Smit (2004) add by describing qualitative studies as those which aim at obtaining depth rather than quantity of understanding phenomena. This is supported by Ezzy (2002) when stating that qualitative methods are those which identify a person's understanding of the situation as something to be discovered rather than assumed. In this study the researcher has therefore decided to utilize this method because he/she wanted to explore, interpret and understand the meaning that the participant makes of a situation/phenomenon i.e. student teachers' perceptions on mentoring during school experience at a high school in Gauteng Province, South Africa.

\section{Sampling Procedure}

Purposeful sampling technique was used as described by Yin (2009) and McMillan and Schumacher (2006) define purposeful sampling as that which increase the utility of information obtained from small samples. The aim of using purposeful sampling in this study was that the researcher did not have access to the entire PGCE students. Secondly the researcher intended to select rich information from the selected participant because he/she is likely to be very knowledgeable and informative about the phenomenon of student teachers' perceptions on mentoring during school experience. The researcher thus selected one student teacher according to his/her availability at the university. The reason was that most of the PGCE student teachers were not available because they were writing June examinations. The purpose of selecting the PGCE student teachers was to enable them to explain their mentoring experience during their practice teaching at the school where they were placed. On this note, the researcher focused on one fourth year PGCE student teacher in order to obtain more detailed information on student teachers' perceptions on mentoring during school experience and teaching practice at high schools. Questions asked were focusing on the perceptions of student teachers on mentoring during seven weeks school experience and teaching practice in high schools in Gauteng Province, South Africa.

\section{Collection and Analysis of Data}

Data collection was conducted through interviews which were constructed in line with the research question. McMillan and Schumacher (2006) categorize interviews into, structured, unstructured, informal, formal, focused and unfocused. As a researcher and mentor in the Post Graduate Certificate Education (PGCE) program, I thus collected data by means of in-depth semi- structured individual interviews where predetermined set of flexible questions were asked. The questions were open-ended, allowing more information from the participant. The reason being that I intended guiding the participant in responding to the questions such as "what is your view on mentoring during school experience?" and "has the mentoring process met your initial expectations?" were posed on mentoring during an interview process to a participant who is doing her/his school experience teaching practice at a high school in Gauteng Province in South Africa. This type of data collection is described by Gillham (2000) as a conversation between people where one person seeks responses 
for a particular purpose. In this study the researcher thus interacted with the participant in order to obtain more information about his/her perception of mentoring during school practice. The flexibility of this type of data collection method assisted me in understanding the participant's perceptions on mentoring during school experience and teaching practice in high schools. A voice recording device was used to record the participant's responses through her/his permission. This process was done during the participant's free time, avoiding disturbing him/her during class time. According to Chireshe (2010) the use of voice recording instrument, gives the researcher ample time to reflect on the gathered data as she/he transcribes them.

The collected data were analyzed in this study in a qualitative manner where content analysis was used as a data analysis strategy. This strategy is relevant in this study because the researcher was able to categorize verbal data through interpretation. This is supported by Merriam (2002) when stating that content analysis means that data is categorized by coding and identifying themes that elucidate a clear understanding of the data collected.

\section{Ethical Issues}

The following ethics were considered:

- Permission to conduct this study was granted by the Ethics committee from the University of Johannesburg.

- Permission to participate in this study was also sought from the student and this was granted.

- Information letters included detailed information on the purpose of the research, how data will be gathered and how material will be stored i.e. for two years after the completion of the research.

- All reasonable efforts were applied in the research process to ensure confidentiality.

- The anonymity of the participant was protected. Participant's details were not made known.

- Participant was informed that participation is voluntary and that he/she can withdraw from the research study at any time without any penalty.

- Participant was told that he/she will receive feedback on research results upon the completion of the study.

\section{Findings and Discussions of the Results}

The student teacher as the participant in this study responded to the questions such as "what is your view on mentoring during school experience?" and has the mentoring process met your initial expectations? by mentioning that his/her teaching practice during school experience was maximally improved by the mentoring process at the school where he/she was doing his/her practice teaching. The reason was that the mentor was always readily available. This clearly emphasizes the idea of scaffolding i.e. helping student teachers to develop and enhance their teaching professional skills. This is supported by Metros and Yang (2006) when mentioning that mentoring helps and supports people to manage their own learning in order to maximize their professional potential, develop their skills, improve their performance, and become the person they want to be.

In this context, it means that mentors are important because they assist during teaching practice through imparting knowledge and skills to the student teachers. This in fact commences first in the classroom setting prior to their teaching practice, e.g. through lesson planning/design and lesson presentation where student teachers are given practical instructions on how to teach ,manage diverse classrooms using different teaching strategies that are relevant to their specific subject content. This is supported by Killen (2007) when for example states that using co-operative learning as a teaching strategy is effective in any teaching and learning situation. From this discussion it can once more be mentioned that mentoring contributes towards student teachers' knowledge and professional development.

\section{Conclusion}

What emerged from the study is that mentors are seen as role models thus enabling student teachers to learn a lot from them. Mentors are viewed as encouragers, supporters and providers of knowledge who provide knowledge and feedback in a friendlier manner as mentioned in the previous section. On this note the researcher therefore states that mentors focus on the emphasis of the provision of advice to develop the professional skills to the beginning teachers, without imposing their own teaching methodologies on student teachers. This is imperative because student teachers will also be encouraged to reflect on what was taught thus leading to the development of professionalism in the teaching and learning situation. 


\section{Recommendations}

From the preceding section it can thus be recommended that:

- More research on the focus area of mentoring student teachers during school experience and teaching practice is certainly warranted

- That there should be more diversity in mentoring that is collaborating with district officials and schools when planning and setting roles and responsibilities for mentors and mentees.

\section{References}

Awaya, A. McEwa, H. Heyler, D. Linsky, S. Lum, D, \& Wakukawa, P.( 2003). Mentoring as a journey, Teaching \& Teacher Education, 20(1), 45-57.

Bernard, J. (2000). Development Handbook.The Mentor's Guide: Facilitating Effective Learning Relationships. Jossey-Bass: SanFransisco.

Bleach, K. (1999). The induction and mentoring of newly qualified teachers. London: Fulton.

Elliot, B., \& Calderhead, J. (1994). Mentoring for teacher development: possibilities and caveats. London: Kogan Page.

Engels, N. (2003). Induction support for beginning teachers. Recommendations for Policy Makers, School Management and Mentors. Brochure issued as a result of a Comnius project.

Fisher, F. (2005). Teacher-Child Interaction in the Teaching of Reading: A Review of Research.Journal of Research in Reading, 28(1), 15-24.

Gillham, B. (2000). The research Interview. London: Continuum.

Hopper, B. (2001). The role of the HEl tutor in initial teacher education school-based placement, Mentoring \& Tutoring, 9(3), 211-222.

Killen, R. (2007). Teaching Strategies for Outcomes Based Education. Pretoria: Juta.

Metros, S. E. \& Yang, C. (2006). The Importance of Mentors. Ohio State University: Ohio University.

Mcmillan, J.H. \& Schumacher, S. (2006). Research in Education: Evidence based enquiry. Allyn and Bacon:Boston.

Merriam, S.B. (2002). Qualitative Research and Case Study Applications in Education. San Fransisco: Jossey-Bass Publishers.

Republic of South Africa. Government Gazette. (1998). vol. 402. No.19537.Pretoria: Government Printers.

Chireshe, R. (2010). Perceptions of teachers on the behavior of adolescents in schools. The anthropology journal of studies and man, 13(2), 61-73.

Tomlinson, P. (1995). Understanding mentoring: reflective strategies for school-based teacher preparation. Buckingham: Open University Press.

Yin, R. (2009). Case study research: design and method. London: Sage.

Zachary, L.J. (2011). The mentor's Guide: Facilitating Effective Learning Relationships. San Fransisco: John Wiley. 
